\title{
Health Insurance and Lifestyle Choices: Identifying Ex Ante Moral Hazard in the US Market
}

\author{
Anderson E. Stanciole \\ Department of Economics and Related Studies, University of York, Heslington, York YO10 5DD, UK. \\ E-mail: aes118@gmail.com
}

There is extensive debate in the literature about the practical significance of ex ante moral hazard in health insurance markets. This paper uses data from the U.S. Panel Study of Income Dynamics (1999-2003) to estimate a structural model of individual choice of insurance coverage and four lifestyle decisions: heavy smoking, heavy drinking, lack of exercise and obesity. The results show that health insurance has significant incentive effects on lifestyle choices, increasing the propensity to heavy smoking, lack of exercise and obesity and decreasing the propensity to heavy drinking. There is also significant correlation between the errors of each equation. The results might have implications for the design of health financing policies.

The Geneva Papers (2008) 33, 627-644. doi:10.1057/gpp.2008.27

Keywords: ex ante moral hazard; health insurance; lifestyle choices; maximum simulated likelihood

\section{Introduction}

Moral hazard is an important concept in health economics that refers to the incentive for individuals that are covered by health insurance to change their behaviour in ways that increase the risk of loss for the insurer. According to Zweifel and Manning, ${ }^{1}$ it is possible to distinguish two types of moral hazard behaviour in health insurance markets. First, under ex ante moral hazard, the risk of loss increases before a medical event as individuals behave in more risky ways, therefore making the loss event more likely to occur. Second, under ex post moral hazard, the individual utilisation of health care services increases after the event as a result of more intensive use of medical resources.

Ehrlich and Becker ${ }^{2}$ were among the first to propose a model describing the complex relationship between health insurance and preventive activities. While some kinds of preventive actions are complementary to market insurance, others can be shown to be substitutes. In some circumstances, health insurance coverage may imply that individuals become less concerned about their future health. This might affect the demand for preventive health services and individual lifestyle choices that influence future health.

\footnotetext{
${ }^{1}$ Zweifel and Manning (2000).

${ }^{2}$ Ehrlich and Becker (1972).
} 
Until recently, there has been a widespread view in the literature that, although a theoretical possibility, ex ante moral hazard has possibly limited practical consequences for health insurance markets. Some authors ${ }^{3}$ have suggested that the welfare loss from ex ante moral hazard is probably small because health insurance offers incomplete coverage. Although the monetary component is covered, there are still significant utility losses in terms of pain and suffering, which reduce individual incentives to engage in harmful activities. ${ }^{4}$ In other words, risk aversion contributes to make indeterminate the effect of insurance coverage on preventive activities. ${ }^{5}$

In the empirical literature, several studies support the view that ex ante moral hazard has limited importance for health insurance markets. Kenkel ${ }^{6}$ studied the influence of private insurance on the demand for preventive health care (breast exams and pap tests), finding important life cycle and schooling effects. Kenkel ${ }^{7}$ finds that the use of preventive services decreases with age, which suggests an adaptation to a shortening payoff period to investment in prevention. Increasing coverage for curative services also increases the demand for preventive care because the out-of-pocket cost is reduced. ${ }^{8}$ This suggests that the two types of care are complements and may serve as substitutes for a patient's own preventive effort.

Courbage and Coulon ${ }^{9}$ investigate how private health insurance affects the demand for preventive care (insured) and individual behaviours (non-insured) in the U.K. Health insurance coverage might increase the demand for insured preventive services simply because the direct cost for the patient is reduced. However, it is unlikely to increase non-insured activities. Therefore, the fact that preventive care is insured while preventive activities are not insured helps to disentangle the ex ante and ex post moral hazard effects. Their results, based on univariate probit regressions that control unobservable characteristics using an instrumental variables strategy, suggest that private health insurance increases the probability of exercising and undergoing breast screening and reduces the probability of smoking. The authors argue that this might be due to the fact that insurance makes individuals more concerned about the risks they are facing.

In recent years, new studies have provided additional evidence on the existence of ex ante moral hazard. Dave and Kaestner ${ }^{10}$ have explored the effect of health insurance on health behaviours in the U.S., arguing that there is a direct (ex ante moral hazard) and indirect effect. The indirect effect works through increased contact with health professionals, which might improve health information and reduce the probability of illness.

\footnotetext{
${ }^{3}$ For example, Kenkel (2000) and Zweifel and Manning (2000).

${ }^{4}$ A similar argument should also apply to workers' compensation. The possibility of serious health consequences should make it unlikely that more generous benefits induce workers to become more reckless. However, several studies have documented this effect.

${ }^{5}$ Zweifel and Manning (2000).

${ }^{6}$ Kenkel (1994).

${ }^{7}$ Ibid.

${ }^{8}$ See also Courbage and Coulon (2004) and Pagán et al. (2007).

${ }^{9}$ Courbage and Coulon (2004).

${ }^{10}$ Dave and Kaestner (2006).
} 
Focusing on the effect of health knowledge on health behaviour, Kenkel ${ }^{11}$ also tests the hypothesis that increased contact with health professionals granted by health insurance might improve health knowledge and decrease the propensity to engage in harmful health-related behaviours. The results show that health knowledge decreases smoking and heavy drinking, and increases exercise, but there is still a significant influence of schooling. This suggests the existence of unobservable factors that affect both schooling and health-related behaviour. Similarly, Zweifel and Manning ${ }^{12}$ comment on the likely endogeneity between insurance coverage and wage income.

A major point in Dave and Kaestner's ${ }^{13}$ study is to consider the exogenous change in insurance status that takes place as people above 65 years old become automatically eligible for Medicare in the U.S. This allows the identification of the ex ante moral hazard since insurance coverage is independent from health-related behaviour. Likewise, Bhattacharya and Sood $^{14}$ research the relation between insurance and obesity. They show that, when premiums are not risk rated for obesity, there is a significant negative externality on non-obese enrollees, which appears because obese enrollees have higher expected medical expenditures.

Another important question relates to the relationship between health risk and insurance demand. Some studies ${ }^{15}$ find evidence of a positive relationship between health risk and insurance demand, which is consistent with the existence of adverse selection in the insurance market. Likewise, Courbage and Rey ${ }^{16}$ argue that the fear of sickness exerts a positive influence on the level of effort to prevent the occurrence of sickness. However, other empirical evidence suggests the opposite, that health risk is negatively associated with insurance coverage. For example, Finkelstein and McGarry ${ }^{17}$ find that individuals who invest more on prevention and therefore have lower risk, also spend more on insurance. This might be explained by "other unobserved characteristics that are positively related to coverage and negatively related to risk occurrence", ${ }^{18}$ for instance, if those who purchase health insurance are more risk-averse. This also provides some support for the idea of propitious selection, which according to Thomas" ${ }^{19}$ is the idea that "purchasing more insurance is sometimes associated with lower risk, not higher risk". ${ }^{20}$

Recent studies $^{21}$ show that lifestyle choices are an important determinant of individual health. Habits like smoking or excess drinking have harmful effects on health status and increase the probability of disease and premature death. As a

${ }^{11}$ Kenkel (1991).

12 Zweifel and Manning (2000).

13 Dave and Kaestner (2006).

14 Bhattacharya and Sood (2006).

${ }^{15}$ For example, Cardon and Hendel (2001) and Bundorf et al. (2005).

${ }^{16}$ Courbage and Rey (2006).

${ }^{17}$ Finkelstein and McGarry (2003).

18 Ibid.

19 Thomas (2007).

${ }^{20}$ See also Pauly and Held (1990), Hemenway (1990, 1992), Chiappori and Salanié (2000), de Meza and Webb (2001) and de Donder and Hindriks (2006).

${ }^{21}$ For example, Contoyannis and Jones (2004) and Balia and Jones (2005). 
630

result, health care expenses are also adversely affected, imposing external costs on society.

Manning et al. ${ }^{22}$ have shown that, apart from the internal costs imposed on the individual and the family, over the lifetime each smoker creates an external cost of 15 cents per pack of cigarettes in terms of increased medical expenses and fire damage, and of lower income taxation. ${ }^{23}$ Some studies suggest that, due to lower life expectancy, smokers on average can expect to make positive net contributions to Social Security. Even after controlling for this, Sloan et al. ${ }^{24}$ estimate the lifetime total social cost of smoking at $\$ 106,000$ for a woman and $\$ 220,000$ for a man. The study by Bhattacharya and Sood $^{25}$ cited above estimates that uniform insurance premiums impose an externality of $\$ 150$ per capita per year on non-obese enrollees resulting from increased health expenditures incurred by obese enrollees.

To date most empirical papers have tended to focus on the demand for preventive services or diagnostic tests. ${ }^{26}$ By focusing on the effect of health insurance on lifestyle choices this study fills an important gap, which has implications for the design of both private plans and public systems of social security. ${ }^{27}$ In particular, to the extent that health insurance coverage induces greater engagement in harmful lifestyle choices, the results suggest that health insurance plans might consider introducing incentives to reduce the possible impact in terms of higher expected costs. This might include, for example, the introduction of risk-rated premiums whereby individual contributions are adjusted according to whether or not the patient engages in harmful activities.

Since this paper focuses on the U.S. institutional background as an illustration for the issue of ex ante moral hazard in health insurance markets, a few words about the American health insurance system are in order. The health insurance coverage system for the adult working-age population in the U.S. is based on a combination of different programmes. The Kaiser Family Foundation ${ }^{28}$ estimates that of the total 260 million U.S. non-elderly population in 2006, 61 per cent were covered by employer-sponsored insurance, 5 per cent by private non-group plans, 16 per cent by Medicaid and other public programmes and 18 per cent were uninsured. In addition, the federal and state governments provide specific coverage programmes for the elderly (Medicare, which automatically covers all persons above 65 years) and for vulnerable populations (Medicaid, which provides coverage for low-income families and other groups). As a general rule, health insurance coverage is not mandatory in most states.

This paper is organised as follows. The following section describes the data set used for this study, the waves of 1999, 2001 and 2003 of the Panel Study of Income Dynamics (PSID). The econometric strategy and the estimated models are discussed in

\footnotetext{
${ }^{22}$ Manning et al. (1991).

${ }^{23}$ In 1986 U.S. dollars. For comparison, the price of a pack of cigarettes was about US\$1.

${ }^{24}$ Sloan et al. (2004).

${ }^{25}$ Bhattacharya and Sood (2006).

${ }^{26}$ For example, Kenkel (1994).

${ }^{27}$ Courbage and Coulon (2004).

${ }^{28}$ Kaiser Family Foundation (2006).
} 
the subsequent section. The penultimate section then presents the results and the final section concludes.

\section{Data}

The data used in this paper comes from the PSID. The PSID is a nationally representative longitudinal study of nearly 8,000 U.S. families, which has been following the same families and individuals since 1968. We analyse the waves of 1999 , 2001 and 2003, which contain the information relative to lifestyle choices, health insurance status and other indicators of health status that are relevant for this analysis. We use a balanced sample of 5,126 individuals. The sample includes only the heads of each household, which are all adult individuals (17 years and above).

Our main dependent variable (insured) is a binary indicator equal to one if the individual is covered by health insurance and zero otherwise. This variable is allowed to change over time. Due to data limitations in the PSID survey it is not possible to identify the type of insurance plan that the individual has, whether employersponsored, private or publicly provided such as Medicare/Medicaid. Moreover, we have no information about the amount of premiums and other co-payments that the individual eventually pays in connection with the insurance coverage. On average 93 per cent of individuals in the sample are covered by health insurance.

Table 1 provides some descriptive statistics separating the sample into insured and uninsured individuals. We notice several differences between the two sub-samples. The uninsured sample can be considered more socio-economically deprived in many aspects. For instance, the average family income is less than half that of the insured sample (US\$25,858 vs. US\$62,609), and the average schooling is also lower. While in the insured sample 20 per cent of the individuals have only primary education and 48 per cent have college education, in the uninsured the proportions are practically inversed (44 and 21 per cent, respectively). The unemployment rate is markedly higher in the uninsured sample (14 per cent vs. 5 per cent in the insured sample), but the proportion of retired people is lower (10 per cent vs. 18 per cent). Finally, the combined proportion of African-American and Hispanic individuals is almost double among the uninsured compared to the insured (57 per cent vs. 32 per cent).

Let us focus on the observed prevalence of the lifestyle choices. In almost all cases, the uninsured tend to lead a less health-conscious lifestyle. They tend to smoke more ( 5 per cent of heavy smokers compared to 3 per cent in the uninsured sample), drink more alcohol ( 8 per cent vs. 4 per cent of heavy drinkers) and to be more sedentary (16 per cent vs. 11 per cent). With respect to the prevalence of obesity, however, the two groups fare very similarly ( 25 per cent vs. 26 per cent).

For almost all health condition indicators the insured group reports higher prevalence rates, both for lifestyle-related (stroke, high blood pressure, diabetes, cancer, heart attack and coronary heart disease) and unrelated conditions (arthritis and loss of mental ability). The proportion of individuals with fair or poor self-assessed health is higher among the uninsured. As the measure of health status is self-assessed, this might be related to differences between the two groups on 
Table 1 Variable definitions and descriptive statistics (mean and standard deviation)

\begin{tabular}{|c|c|c|c|c|}
\hline \multirow[t]{2}{*}{ Variable } & \multirow[t]{2}{*}{ Definition } & \multicolumn{3}{|c|}{ Sample } \\
\hline & & Full & Insured & Uninsured \\
\hline insured & 1 if covered by health insurance, 0 otherwise & $0.93(0.26)$ & & \\
\hline heavy smoker & 1 if smokes $20+$ cigarettes per day, 0 otherwise & $0.03(0.18)$ & $0.03(0.17)$ & $0.05(0.21)$ \\
\hline heavy drinker & 1 if has three or more drinks per day, 0 otherwise & $0.04(0.2)$ & $0.04(0.2)$ & $0.08(0.27)$ \\
\hline sedentary & 1 if never engages light physical activity, 0 otherwise & $0.12(0.32)$ & $0.11(0.32)$ & $0.16(0.37)$ \\
\hline obese & 1 if body mass index equal or above 30,0 otherwise & $0.26(0.44)$ & $0.26(0.44)$ & $0.25(0.43)$ \\
\hline bad & 1 if self assessed health is fair/poor, 0 if good/very good/excellent & $0.16(0.36)$ & $0.15(0.36)$ & $0.19(0.4)$ \\
\hline stroke & 1 if ever diagnosed stroke, 0 otherwise & $0.03(0.17)$ & $0.03(0.17)$ & $0.02(0.12)$ \\
\hline high BP & 1 if ever diagnosed high blood pressure, 0 otherwise & $0.26(0.44)$ & $0.26(0.44)$ & $0.21(0.41)$ \\
\hline diabetes & 1 if ever diagnosed diabetes, 0 otherwise & $0.08(0.28)$ & $0.08(0.28)$ & $0.06(0.24)$ \\
\hline cancer & 1 if ever diagnosed cancer, 0 otherwise & $0.04(0.2)$ & $0.04(0.2)$ & $0.02(0.15)$ \\
\hline lung disease & 1 if ever diagnosed lung disease, 0 otherwise & $0.04(0.19)$ & $0.04(0.19)$ & $0.04(0.21)$ \\
\hline heart attack & 1 if ever diagnosed heart attack, 0 otherwise & $0.04(0.21)$ & $0.05(0.21)$ & $0.02(0.15)$ \\
\hline heart disease & 1 if ever diagnosed coronary heart disease, 0 otherwise & $0.07(0.25)$ & $0.07(0.26)$ & $0.03(0.17)$ \\
\hline emotional & 1 if ever diagnosed emotional problems, 0 otherwise & $0.05(0.23)$ & $0.05(0.23)$ & $0.05(0.21)$ \\
\hline arthritis & 1 if ever diagnosed arthritis or rheumatism, 0 otherwise & $0.18(0.39)$ & $0.19(0.39)$ & $0.12(0.33)$ \\
\hline mental loss & 1 if ever diagnosed loss of mental ability, 0 otherwise & $0.02(0.14)$ & $0.02(0.14)$ & $0.01(0.1)$ \\
\hline score & Sum of emotional, arthritis and mental loss & $0.25(0.51)$ & $0.26(0.52)$ & $0.18(0.43)$ \\
\hline income & Total annual family income & $59,976(79,241)$ & $62,568(81,291)$ & $25,858(26,403)$ \\
\hline male & 1 if male, 0 if female & $0.74(0.44)$ & $0.74(0.44)$ & $0.7(0.46)$ \\
\hline age & Age in years & $46.77(15.18)$ & $47.14(15.29)$ & $41.82(12.71)$ \\
\hline married & 1 if married, 0 otherwise & $0.57(0.5)$ & $0.59(0.49)$ & $0.31(0.46)$ \\
\hline kids & No. of children in the household & $0.91(1.19)$ & $0.93(1.19)$ & $0.7(1.16)$ \\
\hline primary & 1 if primary education, 0 otherwise & $0.21(0.41)$ & $0.2(0.4)$ & $0.44(0.5)$ \\
\hline high school & 1 if high school education, 0 otherwise & $0.33(0.47)$ & $0.33(0.47)$ & $0.35(0.48)$ \\
\hline college & 1 if college education, 0 otherwise & $0.46(0.5)$ & $0.48(0.5)$ & $0.21(0.41)$ \\
\hline
\end{tabular}


Table 1 (continued)

\begin{tabular}{|c|c|c|c|c|}
\hline \multirow[t]{2}{*}{ Variable } & \multirow[t]{2}{*}{ Definition } & \multicolumn{3}{|c|}{ Sample } \\
\hline & & Full & Insured & Uninsured \\
\hline white & 1 if white ethnicity, 0 otherwise & $0.63(0.48)$ & $0.64(0.48)$ & $0.4(0.49)$ \\
\hline black & 1 if black ethnicity, 0 otherwise & $0.29(0.46)$ & $0.28(0.45)$ & $0.42(0.49)$ \\
\hline hispanic & 1 if Hispanic ethnicity, 0 otherwise & $0.05(0.21)$ & $0.04(0.19)$ & $0.14(0.35)$ \\
\hline other race & 1 if other ethnicity, 0 otherwise & $0.03(0.18)$ & $0.04(0.18)$ & $0.03(0.17)$ \\
\hline employed & 1 if currently working, 0 otherwise & $0.74(0.44)$ & $0.74(0.44)$ & $0.72(0.45)$ \\
\hline housekeeper & 1 if currently keeping house, 0 otherwise & $0.03(0.17)$ & $0.03(0.17)$ & $0.03(0.17)$ \\
\hline student & 1 if student, 0 otherwise & $0.01(0.09)$ & $0.01(0.09)$ & $0.01(0.11)$ \\
\hline unemployed & 1 if unemployed or looking for work, 0 otherwise & $0.05(0.22)$ & $0.05(0.21)$ & $0.14(0.35)$ \\
\hline retired & 1 if retired or disabled, 0 otherwise & $0.17(0.38)$ & $0.18(0.38)$ & $0.1(0.29)$ \\
\hline northeast & 1 if lives in Northeast region, 0 otherwise & $0.15(0.36)$ & $0.15(0.36)$ & $0.09(0.29)$ \\
\hline north central & 1 if lives in North Central region, 0 otherwise & $0.25(0.44)$ & $0.26(0.44)$ & $0.21(0.41)$ \\
\hline south & 1 if lives in South region, 0 otherwise & $0.41(0.49)$ & $0.4(0.49)$ & $0.48(0.5)$ \\
\hline west & 1 if lives in West region, 0 otherwise & $0.19(0.39)$ & $0.18(0.39)$ & $0.21(0.41)$ \\
\hline alaska & 1 if lives in Alaska or Hawaii, 0 otherwise & $0(0.06)$ & $0(0.06)$ & $0(0.04)$ \\
\hline metropolitan & 1 if lives in metropolitan area, 0 otherwise & $0.72(0.45)$ & $0.72(0.45)$ & $0.69(0.46)$ \\
\hline urban & 1 if lives in urban area, 0 otherwise & $0.25(0.43)$ & $0.25(0.43)$ & $0.27(0.44)$ \\
\hline rural & 1 if lives in rural area, 0 otherwise & $0.03(0.16)$ & $0.03(0.16)$ & $0.04(0.2)$ \\
\hline wave1 & 1 if year 1999,0 otherwise & $0.33(0.47)$ & $0.33(0.47)$ & $0.36(0.48)$ \\
\hline wave2 & 1 if year 2001,0 otherwise & $0.33(0.47)$ & $0.33(0.47)$ & $0.33(0.47)$ \\
\hline wave3 & 1 if year 2003,0 otherwise & $0.33(0.47)$ & $0.34(0.47)$ & $0.31(0.46)$ \\
\hline
\end{tabular}


individual perception about what constitutes bad health. However, as the health conditions depend on medical diagnosis, this might also be explained by lower access to medical care among the uninsured.

\section{Econometric model}

Our primary interest is to determine the effect of health insurance coverage on the individual propensity to particular lifestyle choices. A natural way to obtain this is to estimate reduced form equations for the lifestyle choices, including health insurance as an explanatory variable. This is essentially the approach implemented by Kenkel ${ }^{29}$ and Courbage and Coulon. ${ }^{30}$

However, the decision to purchase health insurance coverage is intrinsically correlated with lifestyle decisions. In general, we might expect the existence of observable and unobservable individual attributes that influence both health insurance coverage and the choice of lifestyle. Observable characteristics such as age play an important role in shaping these correlated decisions. For the analyst, however, the question is that other unobservable attributes might have the same effect. For instance, it is possible that unobservable attributes such as risk aversion might increase the motivation to obtain health insurance coverage and reduce the willingness to engage in harmful activities. If ignored, this unobservable characteristic might lead to biased estimates.

Several strategies can be used to control such unobservable characteristics. For instance, Courbage and Coulon ${ }^{31}$ use instrumental variables as one method for controlling the unobservable heterogeneity that jointly determine health insurance and health behaviour. Another possible method to control unobserved heterogeneity is to consider an exogenous change in insurance status, and to evaluate how this change might affect the moral hazard variable. Dave and Kaestner ${ }^{32}$ explore the "exogenous variation in health insurance as a result of obtaining Medicare coverage at age 65". They find "limited evidence that obtaining health insurance reduces prevention and increases unhealthy behaviours among elderly people".

Our approach to identifying the effect of health insurance on lifestyle choices is to estimate a system of equations based on the multivariate probit model. ${ }^{33}$ The multivariate probit is a 5-equation recursive model, with a structural equation for health insurance coverage and reduced form equations for each of our four lifestyle choices: heavy smoking, heavy drinking, lack of exercise and obesity. Health insurance is included as explanatory variable in the reduced form equations for lifestyle and the residuals in each equation are allowed to be freely correlated.

Let $y_{i I}$ denote a dummy variable for health insurance status. Also let $\mathrm{Y}_{i l}^{L}=\left\{y_{i 1}, y_{i 2}\right.$, $\left.y_{i 3}, y_{i 4}\right\}$ denote a vector of four dummies representing the lifestyle choices of heavy

\footnotetext{
${ }^{29}$ Kenkel (1994).

${ }^{30}$ Courbage and Coulon (2004).

31 Ibid.

${ }^{32}$ Dave and Kaestner (2006).

${ }^{33}$ See Wilde (2000), Cappelari and Jenkins (2003) and Train (2003).
} 
smoking, heavy drinking, lack of exercise and obesity. The multivariate probit model can be formalised as:

$$
\begin{aligned}
& y_{i I}^{*}=\beta_{I}^{\prime} x_{i I}+\varepsilon_{i I}, \\
& y_{i l}^{*}=\gamma_{l} y_{i I}+\beta_{l}^{\prime} x_{i l}+\varepsilon_{i l}, l=1, \ldots, 4, \\
& y_{i I, l}=\left\{\begin{array}{ll}
1 & \text { if } y_{1 I, l}^{*}>0 \\
0 & \text { otherwise. }
\end{array}\right\} \\
& {\left[\begin{array}{l}
\varepsilon_{1 I} \\
\varepsilon_{11} \\
\varepsilon_{12} \\
\varepsilon_{13} \\
\varepsilon_{14}
\end{array}\right] \stackrel{d}{\longrightarrow} N\left(\left[\begin{array}{l}
0 \\
0 \\
0 \\
0 \\
0
\end{array}\right],\left[\begin{array}{ccccc}
1 & & & & \\
\rho_{1 I} & 1 & & & \\
\rho_{2 I} & \rho_{21} & 1 & & \\
\rho_{3 I} & \rho_{31} & \rho_{32} & 1 & \\
\rho_{4 I} & \rho_{41} & \rho_{42} & \rho_{43} & 1
\end{array}\right]\right) }
\end{aligned}
$$

Estimating univariate probit regressions for the lifestyle choices implicitly ignores the unobserved heterogeneity and assumes that the error terms are uncorrelated $\left(\rho_{j k}=0\right.$ for all $j \neq k$ ). Therefore, the estimates for the effect of insurance on lifestyle choices are biased.

There are, however, some practical difficulties associated with the estimation of multivariate probit. In particular, the log-likelihood function is of the form:

$$
L=\sum_{i=1}^{N} \log \Phi_{5}\left(y_{i I}, y_{i 1}, \ldots, y_{14}, x_{i I}, x_{i 1}, \ldots, x_{i 4}\right)
$$

where $\Phi_{5}$ is the 5-dimensional multivariate standard normal distribution. Therefore, the estimation of the multivariate probit requires the evaluation of a 5-dimensional integral over the distribution of the correlated errors. This integral does not have a closed form solution. Moreover, the elevated number of dimensions implies that traditional methods such as the Gauss-Hermite quadrature cannot be applied.

Our approach to circumvent this problem consists of approximating the loglikelihood function using Maximum Simulated Likelihood. This approach is based on the fact that "a multivariate normal distribution function can be expressed as the product of sequentially conditioned univariate normal distribution functions, which can be easily and accurately evaluated". ${ }^{34}$ In practical terms, the joint distribution of errors is decomposed into independent univariate normal distributions using the Cholesky decomposition. This is achieved by drawing repeated random samples from the error distribution.

There has been considerable argument in the literature about the identification of this model. In this aspect we follow Wilde ${ }^{35}$ who has shown that the only

\footnotetext{
${ }^{34}$ Cappelari and Jenkins (2003, p. 280).

${ }^{35}$ Wilde (2000).
} 
condition for identification of the multivariate probit is that there be sufficient variation in the data, while exclusion restrictions are not necessary. Rashad and Kaestner $^{36}$ use a comparable strategy to identify the causal effect of substance abuse on adolescent sexual activity by controlling for unobserved factors using bivariate probit regressions. Moreover, similarly to Adda and Lechene, ${ }^{37}$ we construct an indicator of the individual underlying health. This indicator (variable score) is based on the indicators for arthritis, emotional problems and loss of mental ability. These conditions are supposedly unrelated to the lifestyle choices but give an indication of the individual underlying health. Therefore, they are expected to influence the demand for health insurance, but not the lifestyle choices, acting as an additional exclusion restriction.

\section{Results}

In addition to the multivariate probit, we have also estimated univariate and bivariate probit regressions. The univariate probit results are interesting to compare with previous studies that have used the same method.

The bivariate probit has a similar structure to the multivariate probit but takes only two equations at a time. That is, we estimate four specifications for the bivariate probit, focusing on health insurance and one of the lifestyle choices at each time. The bivariate probit evaluates a bi-dimensional integral with closed form solution over the distribution of residuals. Therefore, the regressions are estimated without resorting to simulation and can serve as a good benchmark to compare the estimates from the multivariate probit.

\section{Effect of control variables}

Results including estimated coefficients for the univariate, bivariate and multivariate probit models are presented in Tables 2, 3 and 4 respectively. The values shown in the tables represent estimated coefficients. Let us first consider the effect of control variables. Some patterns of effects of control variables are consistently estimated in all three groups of models.

The constructed indicator of underlying health stock exerts positive effect on the propensity to insure, which might be interpreted as a sign of adverse selection. With respect to other health indicators, bad health has no effect on health insurance, perhaps because any correlation is already being captured by the variable score, but is positively associated with heavy smoking, lack of exercise and obesity. In some cases diagnosed health conditions affect the propensity to lifestyle choices. However, this might be due to reverse causality implying that the effects should be interpreted as simple correlations without any causal connotation. Generally we find that diabetes is negatively associated with the propensity to heavy drinking, but positively associated

\footnotetext{
${ }^{36}$ Rashad and Kaestner (2004).

37 Adda and Lechene (2004).
} 
Table 2 Univariate probit regressions

\begin{tabular}{|c|c|c|c|c|c|}
\hline \multirow{2}{*}{$\begin{array}{l}\text { Explanatory } \\
\text { variables }\end{array}$} & \multicolumn{5}{|c|}{ Dependent variables } \\
\hline & insured & heavy smoker & heavy drinker & sedentary & obese \\
\hline insured & & $-0.08(0.11)$ & $-0.19 *(0.078)$ & $-0.12 *(0.06)$ & $0.13^{*}(0.06)$ \\
\hline score & $0.22 * * *(0.049)$ & & & & \\
\hline bad & $-0.09(0.061)$ & $0.37 * * *(0.074)$ & $0.03(0.069)$ & $0.48 * * *(0.043)$ & $0.23 * * *(0.044)$ \\
\hline ln income & $0.44 * * *(0.028)$ & $-0.05(0.035)$ & $-0.01(0.034)$ & $-0.086^{* * *}(0.021)$ & $-0.053 * *(0.02)$ \\
\hline male & $-0.41 * * *(0.065)$ & $0.58 * * *(0.11)$ & $0.82 * * *(0.083)$ & $-0.13 *(0.053)$ & $-0.14 * *(0.055)$ \\
\hline age $31-40$ & $-0.06(0.067)$ & $0.25 *(0.1)$ & $0.08(0.078)$ & $0.16^{* *}(0.057)$ & $0.11 *(0.054)$ \\
\hline age $41-50$ & $-0.06(0.07)$ & $0.37 * * *(0.1)$ & $0.18^{*}(0.076)$ & $0.26^{* * *}(0.057)$ & $-0.02(0.056)$ \\
\hline age $51-64$ & $0.03(0.083)$ & $0.34 * *(0.11)$ & $0.12(0.087)$ & $0.23 * * *(0.065)$ & $-0.15^{*}(0.063)$ \\
\hline age 65 above & $0.75^{* * *}(0.12)$ & $-0.58 * * *(0.17)$ & $-0.1(0.12)$ & $0.32 * * *(0.079)$ & $-0.51 * * *(0.084)$ \\
\hline married & $0.4 * * *(0.06)$ & $-0.27 * * *(0.081)$ & $-0.31 * * *(0.063)$ & $0.08(0.05)$ & $0.09(0.05)$ \\
\hline kids & $0.17 * * *(0.025)$ & $-0.01(0.03)$ & $-0.01(0.025)$ & $0.035 *(0.015)$ & $0(0.016)$ \\
\hline stroke & $0.15(0.15)$ & $-0.09(0.18)$ & $-0.01(0.13)$ & $0.28 * * *(0.083)$ & $-0.27 * *(0.095)$ \\
\hline high BP & $0.04(0.056)$ & $0.01(0.066)$ & $0.1(0.058)$ & $0.02(0.04)$ & $0.53 * * *(0.039)$ \\
\hline diabetes & $0.09(0.091)$ & $-0.19(0.12)$ & $-0.23 *(0.1)$ & $0.05(0.056)$ & $0.54 * * *(0.058)$ \\
\hline cancer & $-0.16(0.12)$ & $-0.06(0.2)$ & $-0.06(0.14)$ & $0.1(0.074)$ & $0.01(0.085)$ \\
\hline lung disease & $-0.03(0.1)$ & $0.45 * * *(0.1)$ & $0.21(0.11)$ & $0.21 * *(0.071)$ & $0.01(0.074)$ \\
\hline heart attack & $-0.08(0.13)$ & $0.04(0.16)$ & $-0.22(0.13)$ & $0.06(0.077)$ & $0.06(0.084)$ \\
\hline heart disease & $0.15(0.11)$ & $-0.07(0.12)$ & $0.02(0.099)$ & $0.04(0.062)$ & $0.09(0.064)$ \\
\hline high school & $0.29 * * *(0.057)$ & $-0.26^{* * *}(0.077)$ & $-0.13 *(0.067)$ & $-0.11 *(0.044)$ & $0.02(0.049)$ \\
\hline college & $0.61 * * *(0.062)$ & $-0.72 * * *(0.09)$ & $-0.28 * * *(0.075)$ & $-0.3^{* * *}(0.047)$ & $-0.04(0.051)$ \\
\hline white & $0.44 * * *(0.078)$ & $1.3 * * *(0.23)$ & $0.24 *(0.1)$ & $-0.29 * * *(0.065)$ & $0.04(0.072)$ \\
\hline black & $0.36^{* * *}(0.083)$ & $0.4(0.25)$ & $0.26^{*}(0.11)$ & $-0.12(0.069)$ & $0.29 * * *(0.076)$ \\
\hline housekeeper & $0.26^{*}(0.13)$ & $-0.6^{*}(0.27)$ & $0.23(0.16)$ & $0.14(0.089)$ & $-0.05(0.092)$ \\
\hline student & $0.1(0.18)$ & $-0.11(0.3)$ & $0.05(0.25)$ & $-0.11(0.19)$ & $-0.48 * *(0.18)$ \\
\hline unemployed & $-0.09(0.075)$ & $0.08(0.11)$ & $0.21 *(0.087)$ & $-0.04(0.066)$ & $-0.05(0.059)$ \\
\hline retired & $0.3 * *(0.092)$ & $-0.01(0.11)$ & $0.02(0.091)$ & $0.14 *(0.058)$ & $0.01(0.059)$ \\
\hline north central & $-0.09(0.082)$ & $0.07(0.095)$ & $-0.03(0.081)$ & $-0.15 * *(0.056)$ & $-0.08(0.058)$ \\
\hline south & $-0.19 *(0.078)$ & $0.05(0.093)$ & $-0.08(0.078)$ & $0.06(0.052)$ & $-0.07(0.056)$ \\
\hline west & $-0.2 *(0.087)$ & $-0.29 *(0.12)$ & $-0.11(0.088)$ & $-0.13 *(0.062)$ & $-0.08(0.063)$ \\
\hline alaska & $0.13(0.46)$ & $-0.11(0.49)$ & $0(0.37)$ & $-0.02(0.27)$ & $-0.43(0.37)$ \\
\hline urban & $0.03(0.054)$ & $0.07(0.068)$ & $0.02(0.058)$ & $0.05(0.04)$ & $0.04(0.041)$ \\
\hline rural & $-0.37 * *(0.12)$ & $0.07(0.15)$ & $0.02(0.15)$ & $-0.07(0.1)$ & $0.17(0.097)$ \\
\hline wave2 & $-0.03(0.039)$ & $-0.13 * * *(0.037)$ & $0.05(0.039)$ & $0.01(0.033)$ & $0.039 *(0.019)$ \\
\hline wave3 & $0(0.042)$ & $-0.18 * * *(0.042)$ & $0.06(0.042)$ & $-0.04(0.034)$ & $0.1 * * *(0.021)$ \\
\hline _cons & $-3.7 * * *(0.29)$ & $-2.4 * * *(0.4)$ & $-2.1 * * *(0.35)$ & $-0.15(0.22)$ & $-0.4(0.22)$ \\
\hline Pseudo $R^{2}$ & 0.22 & 0.16 & 0.06 & 0.11 & 0.073 \\
\hline$N$ & 14,557 & 14,517 & 14,540 & 14,515 & 14,344 \\
\hline$N$ clusters & 5,481 & 5,478 & 5,480 & 5,481 & 5,456 \\
\hline
\end{tabular}

Notes: ${ }^{*} p<0.1 ; * * p<0.05 ; * * * p<0.01$. Cluster-robust standard errors in parentheses.

with the propensity to obesity. Similarly, high blood pressure has a positive association with obesity. There is also positive association of lung disease with heavy smoking and lack of exercise.

With respect to demographic indicators, males are more likely than females to be heavy drinkers and heavy smokers but less likely to be insured and obese. The effect of 
Table 3 Bivariate probit regressions

\begin{tabular}{|c|c|c|c|c|c|}
\hline \multirow{2}{*}{$\begin{array}{l}\text { Explanatory } \\
\text { variables }\end{array}$} & \multicolumn{5}{|c|}{ Dependent variables } \\
\hline & insured $^{\mathrm{a}}$ & heavy smoker & heavy drinker & sedentary & obese \\
\hline insured & & $1.1 * * *(0.25)$ & $-0.66^{*}(0.26)$ & $0.72 * * *(0.2)$ & $0.65^{* *}(0.23)$ \\
\hline score & $0.24 * * *(0.048)$ & & & & \\
\hline bad & $-0.1(0.06)$ & $0.33 * * *(0.073)$ & $0.03(0.068)$ & $0.47 * * *(0.043)$ & $0.22 * * *(0.043)$ \\
\hline ln income & $0.43^{* * *}(0.028)$ & $-0.18 * * *(0.047)$ & $0.02(0.036)$ & $-0.15 * * *(0.028)$ & $-0.089 * * *(0.026)$ \\
\hline male & $-0.4 * * *(0.065)$ & $0.66^{* * *}(0.093)$ & $0.77 * * *(0.086)$ & $-0.04(0.059)$ & $-0.1(0.059)$ \\
\hline age $31-40$ & $-0.04(0.067)$ & $0.23 *(0.092)$ & $0.07(0.078)$ & $0.16^{* *}(0.056)$ & $0.12 *(0.054)$ \\
\hline age $41-50$ & $-0.05(0.07)$ & $0.34 * * *(0.093)$ & $0.17 *(0.076)$ & $0.26 * * *(0.056)$ & $-0.01(0.056)$ \\
\hline age $51-64$ & $0.03(0.083)$ & $0.28 * *(0.1)$ & $0.12(0.086)$ & $0.21 * *(0.065)$ & $-0.15^{*}(0.063)$ \\
\hline age 65 above & $0.75^{* * *}(0.12)$ & $-0.71 * * *(0.15)$ & $-0.08(0.12)$ & $0.22 * *(0.083)$ & $-0.54 * * *(0.085)$ \\
\hline married & $0.41 * * *(0.06)$ & $-0.35 * * *(0.077)$ & $-0.28 * * *(0.064)$ & $0.01(0.054)$ & $0.06(0.052)$ \\
\hline kids & $0.17 * * *(0.025)$ & $-0.05(0.03)$ & $0(0.025)$ & $0.01(0.017)$ & $-0.01(0.017)$ \\
\hline stroke & $0.15(0.15)$ & $-0.12(0.17)$ & $0(0.13)$ & $0.26^{* *}(0.084)$ & $-0.28 * *(0.095)$ \\
\hline high $\mathrm{BP}$ & $0.03(0.055)$ & $-0.01(0.06)$ & $0.1(0.057)$ & $0.01(0.039)$ & $0.52 * * *(0.039)$ \\
\hline diabetes & $0.1(0.09)$ & $-0.18(0.1)$ & $-0.22 *(0.1)$ & $0.03(0.055)$ & $0.53 * * *(0.058)$ \\
\hline cancer & $-0.15(0.12)$ & $0(0.18)$ & $-0.07(0.13)$ & $0.12(0.073)$ & $0.02(0.084)$ \\
\hline lung disease & $-0.06(0.1)$ & $0.39 * * *(0.096)$ & $0.22(0.11)$ & $0.21 * *(0.069)$ & $0.01(0.074)$ \\
\hline heart attack & $-0.1(0.13)$ & $0.05(0.14)$ & $-0.22(0.13)$ & $0.06(0.077)$ & $0.06(0.084)$ \\
\hline heart disease & $0.16(0.11)$ & $-0.1(0.11)$ & $0.02(0.098)$ & $0.03(0.061)$ & $0.08(0.064)$ \\
\hline high school & $0.28 * * *(0.056)$ & $-0.32 * * *(0.07)$ & $-0.11(0.068)$ & $-0.15 * * *(0.045)$ & $-0.01(0.051)$ \\
\hline college & $0.6 * * *(0.061)$ & $-0.79 * * *(0.08)$ & $-0.26 * * *(0.076)$ & $-0.36 * * *(0.049)$ & $-0.07(0.053)$ \\
\hline white & $0.46^{* * *}(0.077)$ & $0.87 * * *(0.26)$ & $0.27 * *(0.1)$ & $-0.35 * * *(0.066)$ & $0(0.073)$ \\
\hline black & $0.37 * * *(0.082)$ & $0.19(0.21)$ & $0.28 *(0.11)$ & $-0.18 *(0.069)$ & $0.26 * * *(0.077)$ \\
\hline housekeeper & $0.25 *(0.12)$ & $-0.59 *(0.23)$ & $0.24(0.15)$ & $0.09(0.088)$ & $-0.07(0.092)$ \\
\hline student & $0.11(0.18)$ & $-0.11(0.25)$ & $0.06(0.24)$ & $-0.13(0.19)$ & $-0.48^{* *}(0.17)$ \\
\hline unemployed & $-0.1(0.074)$ & $0.11(0.098)$ & $0.19 *(0.088)$ & $0(0.064)$ & $-0.03(0.058)$ \\
\hline retired & $0.29 * *(0.089)$ & $-0.12(0.1)$ & $0.04(0.091)$ & $0.08(0.059)$ & $-0.02(0.06)$ \\
\hline north central & $-0.07(0.081)$ & $0.09(0.087)$ & $-0.03(0.08)$ & $-0.14 *(0.056)$ & $-0.08(0.058)$ \\
\hline south & $-0.18 *(0.077)$ & $0.09(0.087)$ & $-0.08(0.077)$ & $0.07(0.051)$ & $-0.06(0.056)$ \\
\hline west & $-0.18 *(0.087)$ & $-0.19(0.12)$ & $-0.11(0.088)$ & $-0.11(0.062)$ & $-0.08(0.063)$ \\
\hline alaska & $0.05(0.41)$ & $-0.15(0.46)$ & $0.01(0.37)$ & $-0.04(0.26)$ & $-0.45(0.36)$ \\
\hline urban & $0.03(0.054)$ & $0.05(0.062)$ & $0.03(0.057)$ & $0.04(0.039)$ & $0.04(0.041)$ \\
\hline Rural & $-0.36 * *(0.13)$ & $0.17(0.14)$ & $0(0.15)$ & $-0.01(0.1)$ & $0.19 *(0.096)$ \\
\hline wave2 & $-0.04(0.039)$ & $-0.1 * *(0.036)$ & $0.05(0.039)$ & $0.01(0.033)$ & $0.041 *(0.019)$ \\
\hline wave3 & $0(0.042)$ & $-0.16^{* * *}(0.04)$ & $0.06(0.042)$ & $-0.04(0.034)$ & $0.1 * * *(0.021)$ \\
\hline _cons & $-3.6^{* * *}(0.29)$ & $-1.6^{* *}(0.55)$ & $-2 * * *(0.34)$ & $-0.07(0.23)$ & $-0.44 *(0.22)$ \\
\hline$\rho$ & & $-0.73 * * *(0.3)$ & $0.25^{* *}(0.129)$ & $-0.48 * * *(0.139)$ & $-0.29^{* *}(0.129)$ \\
\hline$N$ & 14,517 & 14,517 & 14,540 & 14,515 & 14,344 \\
\hline$N$ cluster & 5,478 & 5,478 & 5,480 & 5,481 & 5,456 \\
\hline
\end{tabular}

${ }^{a}$ Estimates from bivariate probit regression for insurance coverage and heavy smoking. Notes: ${ }^{*} p<0.1 ; * * p<0.05 ; * * * p<0.01$. Cluster-robust standard errors in parentheses.

age is a bit contradictory. Compared to adults below 30 years old, those between 41 and 64 years can be considered to engage relatively more in unhealthy lifestyles. Those above 65 years, however, are more likely to be sedentary but less likely to be heavy smokers and obese. This might be explained by survival effects suggesting that individuals with unhealthy lifestyle are less likely to reach old age. The group above 65 
Table 4 Multivariate probit regressions

\begin{tabular}{|c|c|c|c|c|c|}
\hline \multirow{2}{*}{$\begin{array}{l}\text { Explanatory } \\
\text { variables }\end{array}$} & \multicolumn{5}{|c|}{ Dependent variables } \\
\hline & insured & heavy smoker & heavy drinker & sedentary & obese \\
\hline insured & & $0.64 * *(0.222)$ & $-0.38 *(0.191)$ & $0.54 * *(0.171)$ & $0.49 * * *(0.148)$ \\
\hline score & $0.27 * * *(0.044)$ & & & & \\
\hline bad & $-0.12 *(0.054)$ & $0.37 * * *(0.063)$ & $0.03(0.06)$ & $0.47 * * *(0.039)$ & $0.23 * * *(0.036)$ \\
\hline ln income & $0.44 * * *(0.023)$ & $-0.11 * *(0.039)$ & $0(0.029)$ & $-0.14 * * *(0.025)$ & $-0.077 * * *(0.02)$ \\
\hline male & $-0.39 * * *(0.051)$ & $0.63 * * *(0.078)$ & $0.8 * * *(0.07)$ & $-0.06(0.05)$ & $-0.11 * *(0.04)$ \\
\hline age $31-40$ & $-0.04(0.057)$ & $0.24 * *(0.078)$ & $0.08(0.067)$ & $0.16^{* *}(0.055)$ & $0.11 * *(0.041)$ \\
\hline age $41-50$ & $-0.06(0.057)$ & $0.36 * * *(0.076)$ & $0.17 * *(0.065)$ & $0.27 * * *(0.054)$ & $-0.02(0.041)$ \\
\hline age $51-64$ & $0.03(0.067)$ & $0.31 * * *(0.085)$ & $0.14(0.074)$ & $0.22 * * *(0.061)$ & $-0.15^{* *}(0.046)$ \\
\hline age 65 above & $0.78 * * *(0.106)$ & $-0.65 * * *(0.133)$ & $-0.08(0.102)$ & $0.24 * *(0.076)$ & $-0.53 * * *(0.062)$ \\
\hline married & $0.41 * * *(0.049)$ & $-0.31 * * *(0.059)$ & $-0.3 * * *(0.051)$ & $0.02(0.046)$ & $0.07(0.037)$ \\
\hline kids & $0.17 * * *(0.019)$ & $-0.03(0.024)$ & $-0.01(0.019)$ & $0.02(0.015)$ & $0(0.012)$ \\
\hline stroke & $0.09(0.137)$ & $-0.09(0.147)$ & $0.01(0.125)$ & $0.28 * * *(0.072)$ & $-0.29 * * *(0.073)$ \\
\hline high $\mathrm{BP}$ & $0.02(0.049)$ & $0.01(0.055)$ & $0.1^{*}(0.047)$ & $0.02(0.035)$ & $0.53 * * *(0.029)$ \\
\hline diabetes & $0.1(0.077)$ & $-0.19 *(0.093)$ & $-0.27 * *(0.084)$ & $0.03(0.05)$ & $0.52 * * *(0.043)$ \\
\hline cancer & $-0.16(0.112)$ & $-0.03(0.134)$ & $-0.06(0.113)$ & $0.13(0.066)$ & $0.02(0.062)$ \\
\hline lung disease & $-0.07(0.092)$ & $0.41 * * *(0.091)$ & $0.22 *(0.092)$ & $0.22 * * *(0.063)$ & $0(0.06)$ \\
\hline heart attack & $-0.07(0.114)$ & $0.04(0.117)$ & $-0.22(0.115)$ & $0.06(0.067)$ & $0.06(0.061)$ \\
\hline heart disease & $0.15(0.101)$ & $-0.1(0.102)$ & $0.03(0.089)$ & $0.04(0.057)$ & $0.08(0.051)$ \\
\hline high school & $0.28 * * *(0.046)$ & $-0.29 * * *(0.057)$ & $-0.12 *(0.053)$ & $-0.14 * * *(0.039)$ & $0(0.034)$ \\
\hline college & $0.6^{* * *}(0.051)$ & $-0.76^{* * *}(0.064)$ & $-0.26^{* * *}(0.055)$ & $-0.35 * * *(0.042)$ & $-0.06(0.036)$ \\
\hline white & $0.42 * * *(0.066)$ & $1.1 * * *(0.191)$ & $0.28 * *(0.09)$ & $-0.32 * * *(0.058)$ & $0.01(0.051)$ \\
\hline black & $0.35^{* * *}(0.07)$ & $0.28(0.19)$ & $0.29 * *(0.095)$ & $-0.14 *(0.06)$ & $0.27 * * *(0.054)$ \\
\hline housekeeper & $0.22(0.114)$ & $-0.59 *(0.278)$ & $0.21(0.14)$ & $0.13(0.082)$ & $-0.08(0.077)$ \\
\hline student & $0.11(0.182)$ & $-0.07(0.315)$ & $0.04(0.243)$ & $-0.1(0.188)$ & $-0.48 * *(0.161)$ \\
\hline unemployed & $-0.09(0.067)$ & $0.1(0.096)$ & $0.2 *(0.079)$ & $-0.01(0.065)$ & $-0.04(0.054)$ \\
\hline retired & $0.3^{* * *}(0.075)$ & $-0.04(0.084)$ & $0.04(0.073)$ & $0.09(0.053)$ & $-0.01(0.046)$ \\
\hline north central & $-0.04(0.069)$ & $0.09(0.069)$ & $-0.05(0.061)$ & $-0.15^{* *}(0.05)$ & $-0.082 *(0.039)$ \\
\hline south & $-0.15 *(0.065)$ & $0.07(0.069)$ & $-0.1(0.059)$ & $0.06(0.046)$ & $-0.07(0.037)$ \\
\hline west & $-0.16^{*}(0.072)$ & $-0.24 * *(0.088)$ & $-0.12(0.069)$ & $-0.12 *(0.054)$ & $-0.08(0.043)$ \\
\hline alaska & $0.12(0.412)$ & $-0.12(0.342)$ & $0.02(0.288)$ & $-0.06(0.265)$ & $-0.45(0.231)$ \\
\hline urban & $0.05(0.044)$ & $0.08(0.049)$ & $0.04(0.045)$ & $0.05(0.034)$ & $0.04(0.028)$ \\
\hline rural & $-0.35 * * *(0.098)$ & $0.15(0.111)$ & $0.01(0.114)$ & $-0.03(0.093)$ & $0.19 * *(0.071)$ \\
\hline wave2 & $-0.03(0.046)$ & $-0.12 *(0.053)$ & $0.05(0.049)$ & $0.02(0.037)$ & $0.04(0.03)$ \\
\hline wave3 & $0.00(0.047)$ & $-0.18 * *(0.054)$ & $0.04(0.049)$ & $-0.04(0.037)$ & $0.1 * * *(0.03)$ \\
\hline _cons & $-3.8 * * *(0.246)$ & $-2.2^{* * *}(0.393)$ & $-0.2 * * *(0.277)$ & $-0.13(0.212)$ & $-0.43^{*}(0.178)$ \\
\hline$N$ & 14,260 & 14,260 & 14,260 & 14,260 & 14,260 \\
\hline Draws & 130 & 130 & 130 & 130 & 130 \\
\hline
\end{tabular}

Notes: ${ }^{*} p<0.1 ; * * p<0.05 ; * * * p<0.01$. Standard errors in parentheses.

years has a higher propensity to be covered by health insurance reflecting the fact that all individuals in this group are automatically eligible for Medicare. There are few differences between geographical regions but in general it is possible to say that individuals from North, Central and West lead healthier lifestyle, and those from rural areas have lower probability to insurance. We also notice a tendency for reducing heavy smoking and increasing obesity prevalence over time. 
640

Socioeconomic status is important to explain many lifestyle choices. Higher income and education decrease the likelihood to be a heavy smoker, heavy drinker ${ }^{38}$ and sedentary but increases the propensity to health insurance. White people are more heavy smokers and heavy drinkers but less sedentary than other ethnicities. The propensity to obesity is clearly higher among African-Americans. Students have a lower propensity to obesity perhaps due to an association with age and the unemployed are more likely to be heavy drinkers. Again, the retired are more likely to be insured due to automatic Medicare coverage above 65 years.

\section{The effect of insurance on lifestyle choices}

Let us now focus on the effect of insurance coverage on the lifestyle choices. Table 2 shows the estimated coefficients from the univariate probit regressions. The univariate probit is estimated separate and independently and each column corresponds to a different regression. According to this model, insurance coverage has no effect on the propensity to be a heavy smoker, decreases the probability of being a heavy drinker or sedentary and is associated with an increase in the probability of obesity. Only the latter can interpreted as evidence of ex ante moral hazard.

Based on similar results, previous published studies have argued that health insurance does not have an incentive effect in terms of inducing ex ante moral hazard. For example, using an instrumental variable approach, Courbage and Coulon $^{39}$ find that health insurance significantly decreases the probability of smoking and increases the probability of practicing a sport and of undergoing breast screening. The bivariate and multivariate probit models further extend the relevance of unobservable attributes in influencing both stages of individual decision. This framework explicitly recognises that the choice of insurance coverage is related to the choices about lifestyle.

Table 3 presents the bivariate probit estimates, where lifestyle choices are modelled as joint decisions with insurance coverage, allowing for unspecified correlation between the residuals. In the table, lifestyle equations (columns 2-5) are, one at a time, jointly estimated with the insurance coverage. ${ }^{40}$

In effect, the bivariate probit coefficients for insurance coverage are very different from those for the univariate probit. If we assume the bivariate estimates, the effect of insurance on the propensity to heavy drinking remains negative and significant. However, now insurance coverage exerts positive and significant effects on the probability of being a heavy smoker, sedentary and/or obese. This is very distinct from the results of the univariate analysis. This also suggests the existence of ex ante moral

${ }^{38}$ Kenkel (1991) finds that schooling has a positive effect on the total number of drinks. This might be explained either because the stigma of alcohol consumption varies across socioeconomic groups or because better-educated individuals are more aware of the beneficial effects of moderate alcohol consumption.

${ }^{39}$ Courbage and Coulon (2004).

${ }^{40}$ Table 3 reports the insurance equation estimated together with heavy smoking. The results of the insurance equation with the other lifestyle choices are very similar and are available on request. 
hazard in the sense that insured individuals are more likely to be heavy smokers, sedentary and obese.

It is instructive to analyse more closely the correlations between the residuals in the insurance and lifestyle equations $(\rho)$. This gives an estimate of the correlation between unobservable factors that influence both decisions. For instance, we notice a negative correlation between residuals in the heavy smoking and insurance equations. This suggests the existence of unobservable elements which, if they increase the propensity to insure, decrease the propensity to heavy smoking and vice-versa. For example, it might be the case that more risk-averse people (unobservable characteristic) are more likely to purchase health insurance and less likely to be heavy smokers, for fear of the adverse consequences of smoking. ${ }^{41}$ The univariate probit model ignores this channel of correlation, and consequently yields a negative (and incidentally not significant) estimate of the effect of insurance on heavy smoking. The univariate estimate is, nonetheless, biased.

Similarly, the residuals of the insurance equation are also negatively correlated with the residuals of the lack of exercise and obesity equations. Consequently, the univariate probit coefficient of the effect of insurance is negative for lack of exercise and downward biased for obesity.

With respect to heavy drinking, the correlation between residuals is positive, suggesting that unobservable characteristics increase the probability of both insurance coverage and heavy drinking. Therefore, both the univariate and the bivariate probit models estimate negative effects of insurance on heavy drinking, suggesting the absence of ex ante moral hazard in this dimension.

The multivariate probit extends the notion of controlling for unobservable heterogeneity by estimating the correlation of the residuals between all the equations in the recursive system. The five equations are estimated simultaneously and the residuals are allowed to be freely correlated. Estimation is based on the simulation of the multivariate normal distribution of the residuals. We set the number of draws of the simulation to 130 , which is approximately equal to the square root of our pooled sample size of 14,000 individuals. $^{42}$

The results of the multivariate probit can be considered qualitatively similar to the bivariate probit estimates. This is a good robustness indicator since the bivariate probit does not rely on simulation to be estimated. According to the multivariate probit, health insurance increases the propensity to heavy smoking, lack of exercise and obesity, and decreases the propensity to heavy drinking. This suggests the existence of ex ante moral hazard, at least for the first three lifestyle choices.

Table 5 shows the correlation between residuals in all five equations. The first column gives the correlation of residuals in the insurance equation with those in the other four equations, suggesting a similar pattern as the bivariate probit regressions. Unobservable attributes of the insurance decision are negatively correlated to those that influence heavy smoking, lack of exercise and obesity.

\footnotetext{
${ }^{41}$ See Kenkel (1994, p. 320, footnote).

${ }^{42}$ See Cappelari and Jenkins (2003).
} 
The Geneva Papers on Risk and Insurance - Issues and Practice

642

Table 5 Correlation between residuals from multivariate probit regressions

\begin{tabular}{lrrrr}
\hline & \multicolumn{1}{c}{ Insured } & Heavy smoker & Heavy drinker & Sedentary \\
\hline Heavy smoker & $-0.41 * * *(0.128)$ & & & \\
Heavy drinker & $0.09(0.095)$ & $0.33 * * *(0.038)$ & & \\
Sedentary & $-0.37 * * *(0.095)$ & $0.19 * * *(0.040)$ & $0.07 * *(0.032)$ & \\
Obese & $-0.2 * *(0.078)$ & $-0.04(0.035)$ & $-0.06 * *(0.027)$ & $0.09 * * *(0.021)$ \\
\hline
\end{tabular}

Notes: ${ }^{*} p<0.1 ;{ }^{*} p<0.05 ; * * * p<0.01$. Standard errors in parentheses.

Moreover, we notice significant correlation between residuals in the lifestyle equations. We find specifically that unobservable determinants of heavy smoking, heavy drinking and lack of exercise are all positively correlated. Similarly, there is positive association between unobservable determinants of obesity and lack of exercise. This suggests some degree of complementarity between these lifestyle choices. On the other hand, there is significant negative association between unobservable determinants of heavy drinking and obesity, suggesting these choices might be considered substitutes.

\section{Conclusion}

In this paper, we have used data from the 1999, 2001 and 2003 waves of the PSID to explore the effect of health insurance coverage on lifestyle choices. We estimated a structural model of the individual choice of insurance and of four lifestyle-related decisions: heavy smoking, heavy drinking, lack of exercise and obesity.

The underlying correlation between insurance and lifestyle choices is modelled using a multivariate probit. This structural approach assumes that insurance coverage and the four lifestyle choices are sequential and interdependent decisions. Most previous studies ignore this feature and consequently find that health insurance is not an important determinant of lifestyle choices.

The results show that health insurance has significant incentive effects on lifestyle choices, increasing the propensity to heavy smoking, lack of exercise and obesity and decreasing the propensity to heavy drinking. There is also significant correlation between the residuals of each equation. The pattern of correlation suggests that heavy smoking and heavy drinking, and obesity and lack of exercise may be considered complementary lifestyle choices, while heavy drinking and obesity may be considered substitutes.

The results suggest that unobserved heterogeneity plays an important role in the sequential determination of insurance and lifestyle. There is evidence to suggest the existence of ex ante moral hazard in the choice of heavy smoking, lack of exercise and obesity. The results might also have implications for the design of health financing policies. In particular, to the extent that health insurance coverage induces greater engagement in harmful lifestyle choices, the results suggest that health insurance plans might consider introducing incentives to reduce the possible impact in terms of higher expected costs. This might include, for example, the introduction of risk-rated 
premiums whereby individual contributions are adjusted according to whether or not the patient engages in harmful activities.

Incomplete data limit the interpretation of some of the results. For instance, it was not possible to control some characteristics of the insurance plan, such as premium payments, level of coverage and co-payments and to distinguish the type of health insurance coverage, whether public (Medicare/Medicaid), employer-sponsored or individual. However, sensitivity analysis, which restricts the sample to individuals below 65 years old (ineligible to Medicare), suggests that the results are very robust (full results available on request). Our measure of heavy drinking also deserves additional attention, since it is not clear how to compare different individuals in this aspect.

Among the possible extensions, it would be interesting to explore the economic costs associated with this ex ante moral hazard effect. In particular, it would be useful to estimate the additional costs in terms of extra medical care use and health expenditures. Also if it were possible to control health plan characteristics, we would like to simulate the potential to use risk-rated premiums and co-payments in order to induce the adoption of healthier lifestyles.

\section{Acknowledgements}

I thank Philippe Van Kerm, Elanor Colleoni, Monica Szeles and other workshop participants at CEPS/ INSTEAD Luxembourg in March 2007, the editor and three anonymous referees for helpful comments on the paper. This research was co-funded by the Coordenação de Aperfeiçoamento de Pessoal de Nível Superior of the Ministry of Education of Brazil (Grant no. 147402-2) and the European Commission under the 6th Framework Programme's Research Infrastructures Action (Trans-national access contract RITA 026040) hosted by IRISS-C/I at CEPS/INSTEAD in Luxembourg.

\section{References}

Adda, J. and Lechene, V. (2004) On the identification of the effect of smoking on mortality, Department of Economics Discussion Paper 184, University of Oxford, UK.

Balia, S. and Jones, A. (2005) Mortality, life style and socio-economic status, HEDG WP05/02, UK: University of York.

Bhattacharya, J. and Sood, N. (2006) 'Health insurance and the obesity externality', in K. Bolin and J. Cawley (eds) Advances in Health Economics and Health Services Research (Vol. 17) The Economics of Obesity, Amsterdam: Elsevier.

Bundorf, M., Herring, B. and Pauly, M. (2005) Health risk, income, and the purchase of private health insurance, NBER Working Paper 11677, Washington, DC.

Cappelari, L. and Jenkins, S. (2003) 'Multivariate probit regression using simulated maximum likelihood', The Stata Journal 3: 278-294.

Cardon, J. and Hendel, I. (2001) 'Asymmetric information in health insurance: Evidence from the national medical expenditure survey', RAND Journal of Economics 32: 408-427.

Chiappori, P.-A. and Salanié, B. (2000) 'Testing for asymmetric information in insurance markets', Journal of Political Economy 108: 56-78.

Contoyannis, P. and Jones, A. (2004) 'Socio-economic status, health and life style', Journal of Health Economics 23: 965-995.

Courbage, C. and de Coulon, A. (2004) 'Prevention and private health insurance in the UK', The Geneva Papers on Risk and Insurance - Issues and Practice 29: 719-727.

Courbage, C. and Rey, B. (2006) 'Prudence and optimal prevention for health risks', Health Economics 15: $1323-1327$. 
Dave, D. and Kaestner, R. (2006) Health insurance and ex ante moral hazard: Evidence from the Medicare, NBER Working Paper 12764, Washington, DC.

de Donder, P. and Hindriks, J. (2006) Does propitious selection explain why riskier people buy less insurance? Discussion Paper 06-17, Département des Sciences Économiques de l'Université Catholique de Louvain.

de Meza, D. and Webb, D. (2001) 'Advantageous selection in insurance markets', RAND Journal of Economics 32: 249-262.

Ehrlich, I. and Becker, G. (1972) 'Market insurance, self-insurance, and self-protection', Journal of Political Economy 80: 623-649.

Finkelstein, A. and McGarry, K. (2003) Private information and its effect on market equilibrium: New evidence from long-term care insurance, NBER Working Paper 9957, Washington, DC.

Hemenway, D. (1990) 'Propitious selection', The Quarterly Journal of Economics 105: 1063-1069.

Hemenway, D. (1992) 'Propitious selection in insurance', Journal of Risk and Uncertainty 5: 247-251.

Kaiser Family Foundation (2006) 'Health Insurance Coverage in America 2006', accessed on 4 July 2008, available at http://facts.kff.org/chartbook.aspx?cb $=50$.

Kenkel, D. (1991) 'Health behavior, health knowledge, and schooling', The Journal of Political Economy 99 : 287-305.

Kenkel, D. (1994) 'The demand for preventive medical care', Applied Economics 26: 313-325.

Kenkel, D. (2000) 'Prevention', in A. Culyer and J. Newhouse (eds) Handbook of Health Economics, Amsterdam: Elsevier.

Manning, W., Keeler, E., Newhouse, J., Sloss, E. and Wasserman, J. (1991) The Costs of Poor Health Habits, Cambridge: Harvard University Press.

Pagán, J., Puig, A. and Soldo, B. (2007) 'Health insurance coverage and the use of preventive services by Mexican adults', Health Economics 16: 1359-1369.

Pauly, M. and Held, P. (1990) 'Benign moral hazard and the cost-effectiveness analysis of insurance coverage', Journal of Health Economics 9: 447-461.

Rashad, I. and Kaestner, R. (2004) 'Teenage sex, drugs and alcohol use: Problems identifying the cause of risky behaviour', Journal of Health Economics 23: 493-503.

Sloan, F., Ostermann, J., Picone, G., Conover, C. and Taylor, D. (2004) The Price of Smoking, Cambridge: MIT Press.

Thomas, G. (2007) 'Some novel perspectives on risk classification', The Geneva Papers on Risk and Insurance Issues and Practice 32: 105-132.

Train, K. (2003) Discrete Choice Methods with Simulation, Cambridge: Cambridge University Press.

Wilde, J. (2000) 'Identification of multiple equation probit models with endogenous dummy regressors', Economics Letters 69: 309-312.

Zweifel, P. and Manning, W. (2000) 'Moral hazard and consumer incentives in health care', in A. Culyer and J. Newhouse (eds) Handbook of Health Economics, Amsterdam: Elsevier.

\section{About the Author}

Anderson E. Stanciole is a health economist with experience in health systems financing in international organisations. He received a B.A. (1998) and a M.A. (2002) in Economics from the Universidade de São Paulo, Brazil and a Ph.D. (2007) in Health Economics from the University of York, U.K. 